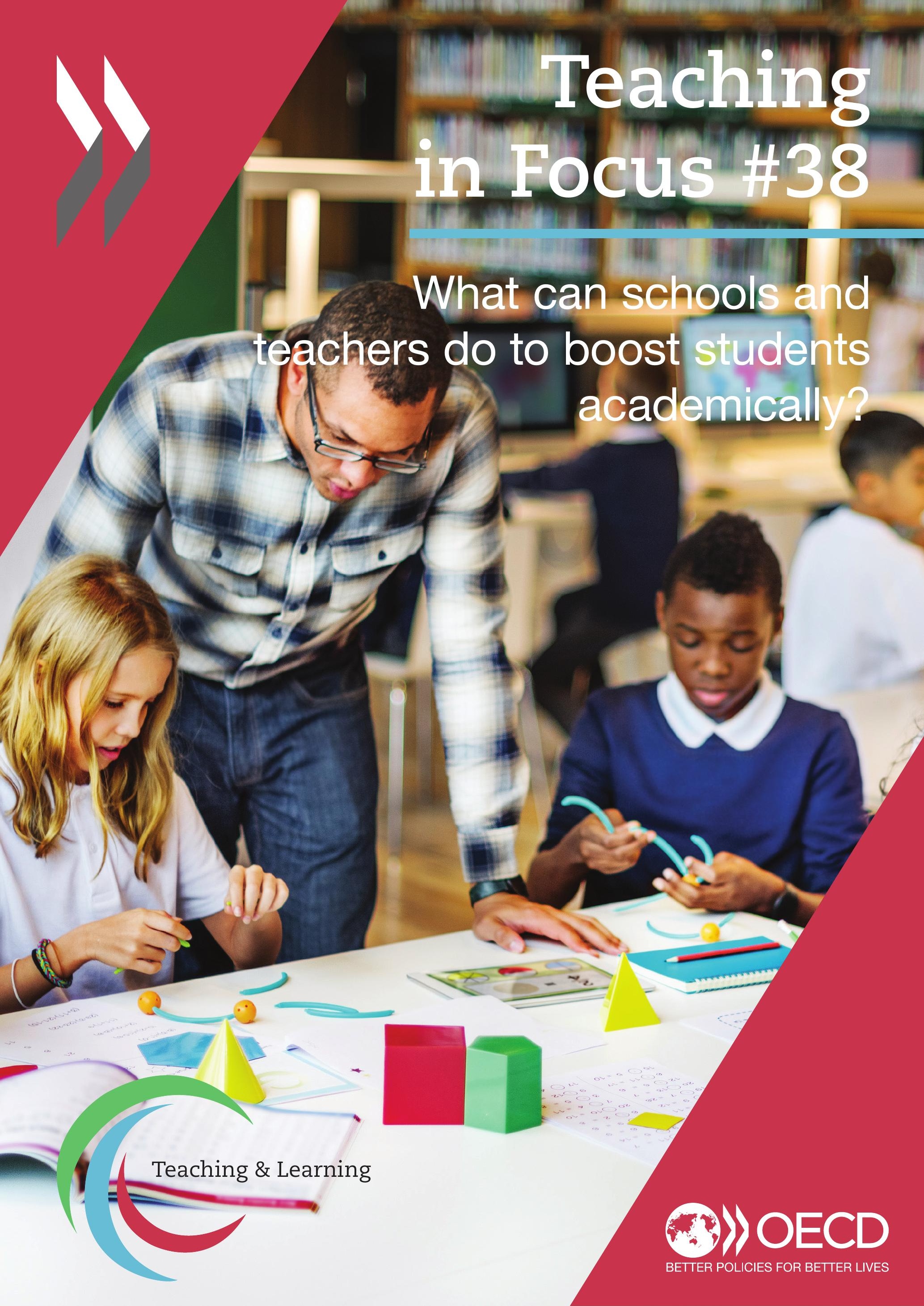




\section{What can schools and teachers do to boost students academically?}

- Students improve academically the more class time teachers spend on actually teaching (as opposed to administrative tasks or disciplinary measures).

- The happier teachers are with their work environment, the better their students perform academically.

- Students in classes with a higher concentration of students from socio-economically disadvantaged homes perform worse academically.

- Students perform better the more academically gifted classmates they have. This may signal the presence of peer effects but also the presence of academic segregation.

With most students around the world having experienced remote learning over the past year because of the COVID-19 pandemic, the importance of teachers and schools has become all the more evident. Temporary school closures underline how richly students benefit from being in school with their teachers and classmates.

Positive, High-achieving Students? What Schools and Teachers Can Do pinpoints some of the factors that make an effective teacher and school.

\section{What is TALIS?}

The OECD Teaching and Learning International Survey (TALIS) is the largest international and periodic survey asking teachers and school leaders about their working conditions and learning environments. The OECD Programme for International Student Assessment (PISA), which provides the most comprehensive and rigorous international assessment of student learning outcomes to date, delivers insights into the cognitive and social-emotional skills of 15 -year-old students by focusing on students' competencies and on how well these competences are applied in different contexts.

Bringing together TALIS and PISA, the TALIS-PISA link comprises data from schools that took part in both surveys. In so doing, it links how 15-year-old students participating in PISA performed on the tests and responded to questions about their socio-emotional profile with the practices, opinions and characteristics of teachers and school principals in the students' schools. By applying a machine learning technique to this unique dataset, we identified teacher and school factors that matter the most for student achievement.

The TALIS-PISA link features student assessment results, and survey responses from students, teachers and school principals from nine countries and economies: Australia, Ciudad Autónoma de Buenos Aires (referred to as CABA [Argentina]), Colombia, the Czech Republic, Denmark, Georgia, Malta, Turkey and Viet Nam.

The key features of the TALIS-PISA link 2018 are as follows:

- Representative samples of schools and 15-year-old students within schools with a target nominal sample size of 150 schools per country and 35 students in each school. In each PISA participating school, the school principal and a random sample of 20 teachers teaching 15 year-old students were selected.

- The TALIS-PISA link only allows data from the teachers teaching 15-year-old students in a school to be matched with the data from 15-year-old students from that same school, but not the data from teachers with that of their own students.

- The TALIS and PISA surveys are cross-sectional, i.e. they measure student, teacher, principal and school characteristics in many countries, but at a single date. This survey design prevents causal interpretation of the analyses based on the TALIS-PISA link data.

- The TALIS questionnaires and PISA assessments and questionnaires were administered during the school year of 2017/18 before the COVID-19 pandemic. 


\section{Make the most of teachers' class time}

What teachers do in their classrooms matters for student achievement. Students tend to perform better on average the more class time school teachers spend on actual teaching and learning. This holds for all three subjects, on average across the countries and economies participating in the TALIS-PISA link and in the Czech Republic and Turkey (Figure 1). When teachers do not actually teach and students do not learn in class, it is usually due to disciplinary issues or administrative tasks. But there may also be a reverse causal relationship here: disruptive classrooms are more likely to have lower-achieving students, which, in turn, leads to more time spent keeping order or carrying out administrative tasks.

In consultation with the school leader and other colleagues, teachers can maximise class time spent on teaching and learning by finding alternative ways of dealing with administrative tasks. Another finding shows that they can improve relationships with students who have disciplinary problems by getting involved in extracurricular activities with their students. That said, teachers' workload should not be increased to include more extracurricular activities unless the time they spend on activities such as administrative work, which is less effective for student development, is reduced.

Figure 1. Relationship between class time spent on teaching and student achievement

Change in PISA score associated with the average class time spent on actual teaching and learning at the school, by subject

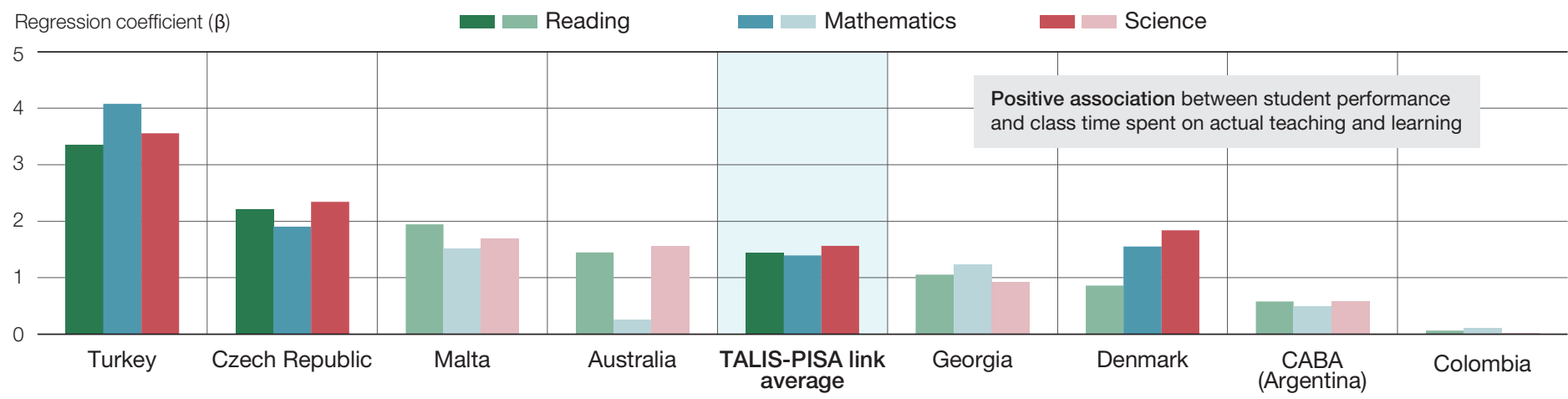

Notes: Teacher variables are averaged for all teachers within the school.

Results of linear regression based on responses of 15-year-old students and teachers. Controlling for other classroom practices of teachers and for the following student characteristics: gender, immigrant background and index of economic, social and cultural status.

Statistically significant coefficients are marked in a darker tone.

Countries and economies are ranked in descending order of the change in PISA reading score associated with the average class time spent on actual teaching and learning at the school.

Source: Adapted from OECD (2021), Positive, High-achieving Students?: What Schools and Teachers Can Do, TALIS, OECD Publishing, Paris, https://doi.org/10.1787/3b9551db-en, Figure 2.5.

\section{Pay attention to teachers' job satisfaction}

Teachers' job satisfaction also matters for student performance. The happier teachers are with their work environment, the better students tend to perform in school on average across participating countries and economies, as well as in Australia, the Czech Republic, Georgia and Turkey (Figure 2). However, self-enforcing dynamics may also be at work here: teachers may be particularly satisfied with the workplace when they work in schools attended by high-achieving students. And, in turn, they may be particularly committed to helping their academically gifted students progress further.

School leaders and educational authorities could work with teachers to identify working conditions that need to be improved. For instance, schools and educational authorities should ensure that teachers have the required infrastructure and materials they need to deliver their subject lessons, especially in the most disadvantaged schools. Yet, there is more to teacher's satisfaction with the work environment than material resources. School leaders can foster a school climate conducive to collaboration, give teachers more autonomy over the core aspects of their work, as well as involve teachers in school decision making. 
Figure 2. Relationship between teachers' satisfaction with work environment and student achievement Change in PISA score associated with the average job satisfaction with work environment at the school, by subject

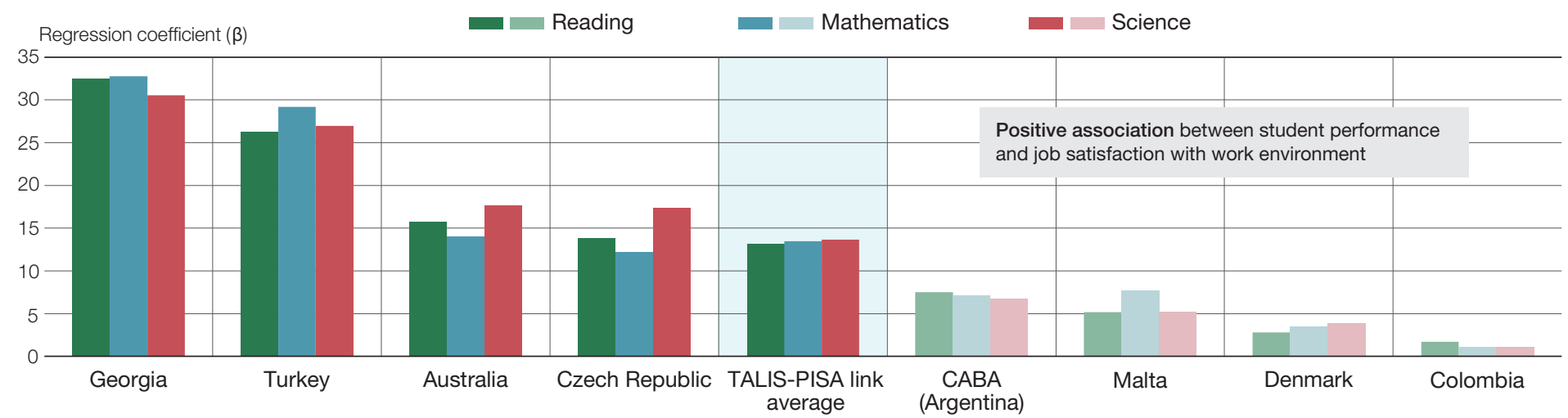

Notes: Teacher variables are averaged for all teachers within the school.

Results of linear regression based on responses of 15-year-old students and teachers. Controlling for the other aspects of well-being and job satisfaction and for the following student characteristics: gender, immigrant background and index of economic, social and cultural status.

Statistically significant coefficients are marked in a darker tone.

Countries and economies are ranked in descending order of the change in PISA reading score associated with the average job satisfaction with work environment at the school. Source: Adapted from OECD (2021), Positive, High-achieving Students?: What Schools and Teachers Can Do, TALIS, OECD Publishing, Paris, https://doi.org/10.1787/3b9551db-en, Figure 2.6.

\section{Optimise class grouping}

Classmates make a difference too. Classes composed of either more socio-economically disadvantaged students or more academically gifted students matter for student achievement. The greater the average concentration of students from socio-economically disadvantaged homes in the classroom, the worse students tend to perform academically in Australia, Colombia and Georgia (Figure 3). Since this finding holds while accounting for students' own socio-economic background, it suggests the presence of peer effects. A student's performance can be negatively affected if the student is surrounded by classmates with limited social, economic and cultural resources, reflecting significant disadvantages in the local community. Fewer available material learning resources at the school and altered teaching strategies may also affect the student's cognitive development. On the other hand, students of any socio-economic background have an academic advantage if they attend a school whose students are from better-off socio-economic backgrounds. In fact, as the average concentration of academically gifted students in the classroom increases, students tend to perform better on average across participating countries and economies, as well as in Australia, CABA (Argentina), the Czech Republic and Turkey (Figure 3). This may signal the presence of academic segregation, as well as peer effects. Students perform better when they are surrounded by classmates with higher innate ability: they are more motivated and competitive, and have higher career aspirations.

Schools could optimise the way students are grouped within classes in a way that benefits the most fragile students without being detrimental to the strongest students. Schools should strive to spread out both academically gifted students and students with disadvantaged socio-economic backgrounds as equally as possible across classes. 
Figure 3. Relationship between classmates' characteristics and student achievement

Change in PISA score associated with the average concentration of students, by characteristics and subject

\section{A. Students from socio-economically disadvantaged homes}

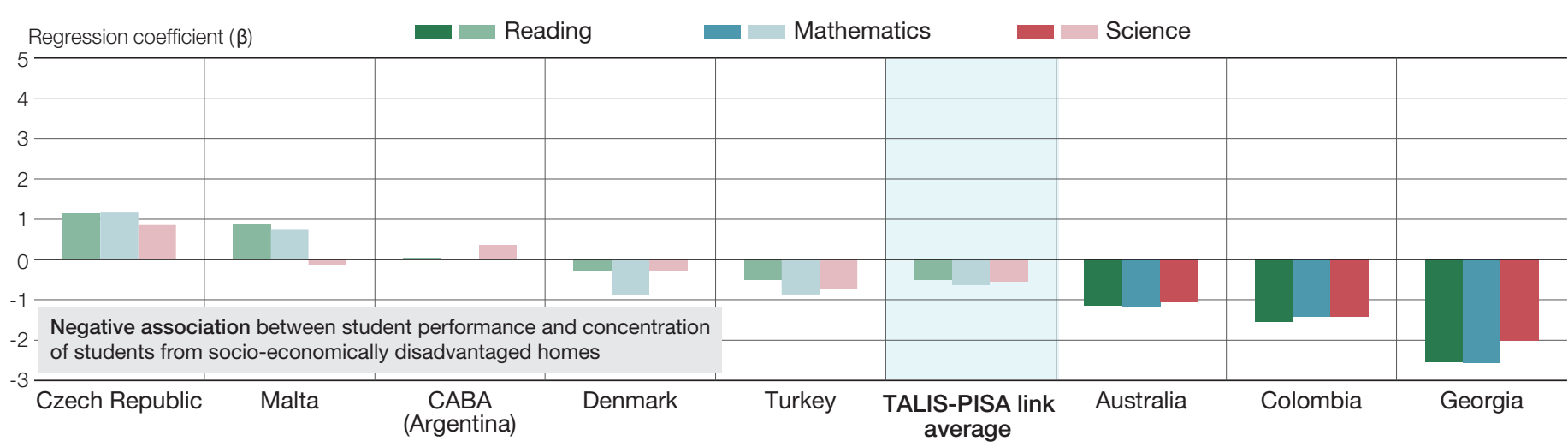

Regression coefficient $(\beta)$

B. Academically gifted students

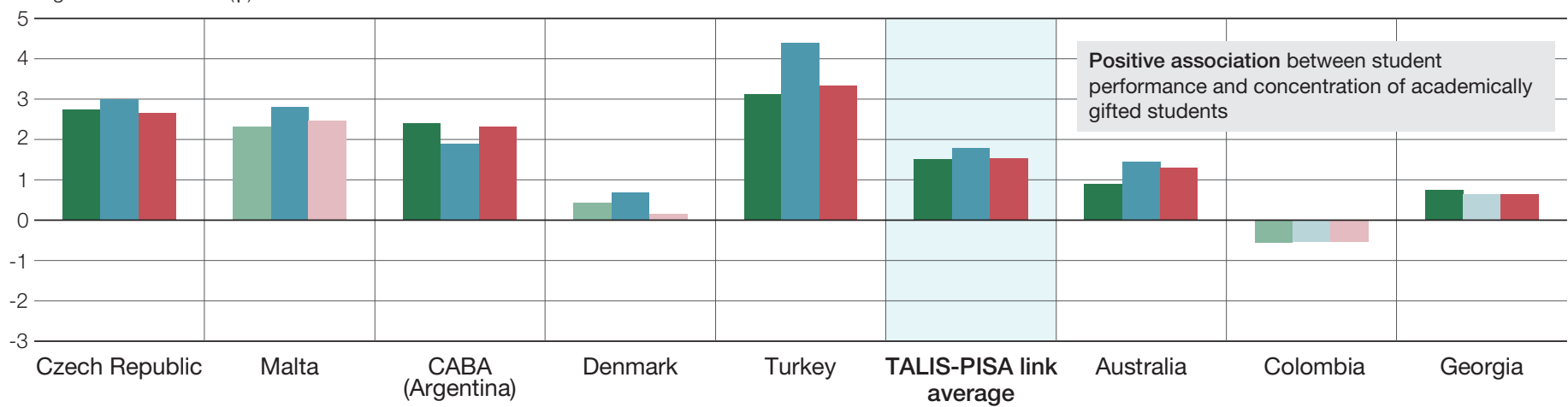

Notes: Teacher variables are averaged for all teachers within the school.

Results of linear regression based on responses of 15-year-old students and teachers. Controlling for other classroom characteristics and for the following student characteristics: gender, immigrant background and index of economic, social and cultural status.

Statistically significant coefficients are marked in a darker tone.

Countries and economies are ranked in descending order of the change in PISA reading score associated with the average concentration of students from socio-economically disadvantaged homes at the school.

Source: Adapted from OECD (2021), Positive, High-achieving Students?: What Schools and Teachers Can Do, TALIS, OECD Publishing, Paris, https://doi.org/10.1787/3b9551db-en, Figures 2.8 and 2.9.

\section{The bottom line}

Mixing students from different socio-economic backgrounds and innate abilities in classrooms, making sure that teachers are happy, and allowing them to spend most of their classroom time teaching are all factors that help students perform better academically.

Not only do these factors matter for student achievement but they are well within reach of policy levers. 


\section{Contact}

Gabor Fulop (gabor.fulop@oecd.org) and talis@oecd.org

\section{For more information}

OECD (2021), Positive, High-achieving Students?: What Schools and Teachers Can Do, TALIS, OECD Publishing, Paris, https://doi.org/10.1787/3b9551db-en.

This paper is published under the responsibility of the Secretary-General of the OECD. The opinions expressed and the arguments employed herein do not necessarily reflect the official views of OECD member countries.

This document, as well as any data and map included herein, are without prejudice to the status of or sovereignty over any territory, to the delimitation of international frontiers and boundaries and to the name of any territory, city or area.

You can copy, download or print OECD content for your own use, and you can include excerpts from OECD publications, databases and multimedia products in your own documents, presentations, blogs, websites and teaching materials, provided that suitable acknowledgment of OECD as source and copyright owner is given. All requests for commercial use and translation rights should be submitted to rights@oecd.org.

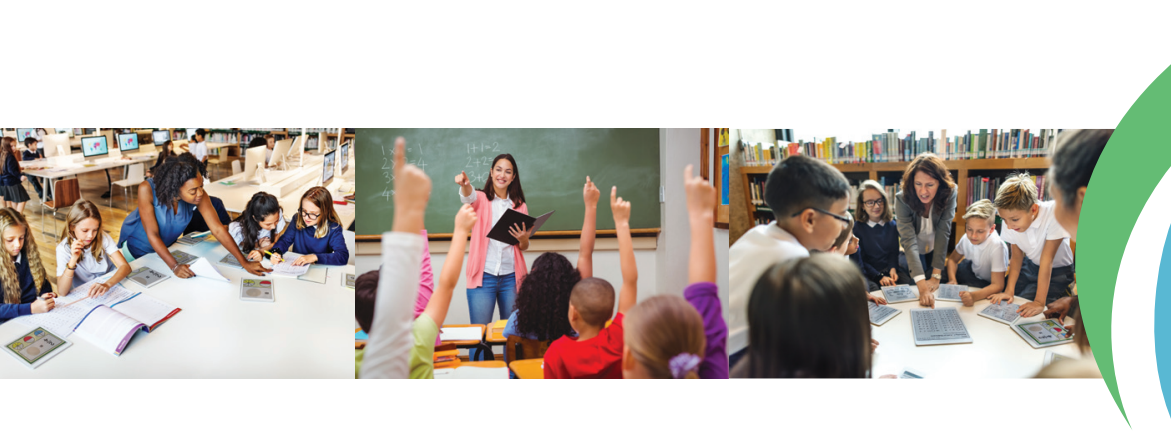

